University of South Carolina

Scholar Commons

\title{
Dynamic path bifurcation for the Beckmann reaction: observation and implication
}

\author{
H. Yamataka \\ M. Sato \\ H. Hasegawa \\ Salai Cheettu Ammal \\ University of South Carolina - Columbia, ammal@cec.sc.edu
}

Follow this and additional works at: https://scholarcommons.sc.edu/eche_facpub

Part of the Biological and Chemical Physics Commons, and the Physical Chemistry Commons

\section{Publication Info}

Published in Faraday Discussions, Volume 145, 2010, pages 327-340.

(C) Faraday Discussions 2010, Royal Society of Chemistry Yamataka, H., Sato, M., Hasegawa, H., Ammal, S. C. (2010). Dynamic path bifurcation for the Beckmann reaction: observation and implication. Faraday Discussions, 145, 327-340.

http://dx.doi.org/10.1039/B906159B

This Article is brought to you by the Chemical Engineering, Department of at Scholar Commons. It has been accepted for inclusion in Faculty Publications by an authorized administrator of Scholar Commons. For more information, please contact digres@mailbox.sc.edu. 
Faraday

Discussions

\section{This paper is published as part of Faraday Discussions volume 145: Frontiers in Physical Organic Chemistry}

Spiers Memorial Lecture

Interplay of theory and computation in chemistry-
examples from on-water organic catalysis, enzyme
catalysis, and single-molecule fluctuations
R. A. Marcus, Faraday Discuss., 2010
DOI: $10.1039 /$ b920917b
Papers

The kinetics and mechanisms of organic reactions in liquid ammonia

Pengju Ji, John H. Atherton and Michael I. Page, Faraday

Discuss., 2010

DOI: $10.1039 / \mathrm{b} 912261 \mathrm{n}$

Interrogation of a dynamic multi-catalyst ensemble in asymmetric catalysis

Julian Eastoe, Ian J. S. Fairlamb, Jesús M. FernándezHernández, Emane Filali, John C. Jeffery, Guy C. LloydJones, Aina Martorell, Antony Meadowcroft, Per-Ola Norrby, Thomas Riis-Johannessen, David A. Sale and Paula M.

Tomlin, Faraday Discuss., 2010

DOI: $\underline{10.1039 / \mathrm{b} 910022 \mathrm{a}}$

Valence bond modelling and density functional theory calculations of reactivity and mechanism of cytochrome P450 enzymes: thioether sulfoxidation

Sason Shaik, Yong Wang, Hui Chen, Jinshuai Song and Rinat Meir, Faraday Discuss., 2010

DOI: $10.1039 /$ b906094d

The EVB as a quantitative tool for formulating simulations and analyzing biological and chemical reactions

Shina C. L. Kamerlin and Arieh Warshel, Faraday Discuss., 2010

DOI: $10.1039 / \mathrm{b} 907354 \mathrm{j}$

On the catalytic role of structural fluctuations in enzyme reactions: computational evidence on the formation of compound 0 in horseradish peroxidase

Costantino Zazza, Amedeo Palma, Andrea Amadei, Nico

\author{
Sanna, Simone Tatoli and Massimiliano Aschi, Faraday \\ Discuss., 2010 \\ DOI: $10.1039 / \mathrm{b} 906614 \mathrm{~d}$ \\ Discussion
}

General discussion

Faraday Discuss., 2010

DOI: $10.1039 / \mathrm{b} 921484 \mathrm{~b}$

Papers

Methylene-transfer reactions of benzylium/tropylium ions with neutral toluene studied by means of ion-trap mass spectrometry

Emilie-Laure Zins, Claude Pepe and Detlef Schröder, Faraday Discuss., 2009

DOI: $\underline{10.1039 / \mathrm{b} 907236 \mathrm{e}}$

Ultrafast time-resolved transient infrared and resonance Raman spectroscopic study of the photo-deprotection and rearrangement reactions of $p$-hydroxyphenacyl caged phosphates

Qian Cao, Xiangguo Guan, Michael W. George, David Lee Phillips, Chensheng Ma, Wai Ming Kwok, Mingde Li, Yong Du, Xue-Zhong Sun and Jiadan Xue, Faraday Discuss., 2010 DOI: $10.1039 / \mathrm{b} 908188 \mathrm{~g}$

Ultrafast reaction dynamics in nanoscale water droplets confined by ionic surfactants

Minako Kondo, Ismael A. Heisler and Stephen R. Meech,

Faraday Discuss., 2010

DOI: $10.1039 / \mathrm{b} 906035 \mathrm{a}$

New host-guest chemistry of supramolecular nanotubes Emiliano Tamanini, Nandhini Ponnuswamy, G. Dan Panto\$ and Jeremy K. M. Sanders, Faraday Discuss., 2010 DOI: $\underline{10.1039 / \mathrm{b} 907538 \mathrm{k}}$

The effect of multivalent binding on the lateral phase separation of adhesive lipids

Kwan Ping Liem, Gavin T. Noble, Sabine L. Flitsch and Simon 
J. Webb, Faraday Discuss., 2010

DOI: $\underline{10.1039 / b 907114 h}$

Designing instructable networks using synthetic replicators

Eleftherios Kassianidis, Russell J. Pearson, Evan A. Wood and Douglas Philp, Faraday Discuss., 2010

DOI: $10.1039 / \mathrm{b} 915061 \mathrm{~g}$

Discussion

General discussion

Faraday Discuss., 2010

DOI: $10.1039 /$ b921489p

Papers

Phosphate ester analogues as probes for understanding enzyme catalysed phosphoryl transfer

Abdulfattah Alkherraz, Shina C. L. Kamerlin, Guoqiang Feng, Qaiser I. Sheikh, Arieh Warshel and Nicholas H. Williams, Faraday Discuss., 2010

DOI: $10.1039 / \mathrm{b} 908398 \mathrm{~g}$

$\underline{\text { Radicals in enzymatic catalysis-a thermodynamic }}$ perspective

Johnny Hioe and Hendrik Zipse, Faraday Discuss., 2010

DOI: $10.1039 / \mathrm{b} 907121 \mathrm{k}$

The application of No Barrier Theory to the aldol addition reaction

J. Peter Guthrie, Alexander R. Bannister and Sriyawathie

Peiris, Faraday Discuss., 2010

DOI: $10.1039 / \mathrm{b} 906718 \mathrm{c}$

Dynamic path bifurcation for the Beckmann reaction: observation and implication

Hiroshi Yamataka, Makoto Sato, Hiroto Hasegawa and Salai

C. Ammal, Faraday Discuss., 2010

DOI: $10.1039 / \mathrm{b} 906159 \mathrm{~b}$

Oxidation of alcohols using supported gold and goldpalladium nanoparticles

Sankar Meenakshisundaram, Ewa Nowicka, Peter J.

Miedziak, Gemma L. Brett, Robert L. Jenkins, Nikolaos

Dimitratos, Stuart H. Taylor, David W. Knight, Donald Bethell and Graham J. Hutchings, Faraday Discuss., 2010

DOI: $10.1039 / \mathrm{b} 908172 \mathrm{k}$

Structure and dynamics of phospholipid bilayer films under electrochemical control

A. Robert Hillman, Karl S. Ryder, Elena Madrid, Andrew W.

Burley, Richard J. Wiltshire, James Merotra, Michaela Grau,

Sarah L. Horswell, Andrew Glidle, Robert M. Dalgliesh,

Arwel Hughes, Robert Cubitt and Andrew Wildes, Faraday

Discuss., 2010

DOI: $10.1039 / \mathrm{b} 911246 \mathrm{~b}$
Discussion

General discussion

Faraday Discuss., 2010

DOI: $\underline{10.1039 / b 921490 a}$

Papers

Ultrafast dynamics of malachite green at the air/water interface studied by femtosecond time-resolved electronic sum frequency generation (TR-ESFG): an indicator for local viscosity

Pratik Sen, Shoichi Yamaguchi and Tahei Tahara, Faraday

Discuss., 2010

DOI: $10.1039 / \mathrm{b} 908097 \mathrm{j}$

Probing the effect of the solution environment on the vibrational dynamics of an enzyme model system with ultrafast 2D-IR spectroscopy

G. M. Bonner, A. R. Ridley, S. K. Ibrahim, C. J. Pickett and N.

T. Hunt, Faraday Discuss., 2010

DOI: $10.1039 / \mathrm{b} 906163 \mathrm{k}$

Understanding solvent effects on structure and reactivity of organic intermediates: a Raman study

G. Balakrishnan, S. K. Sahoo, B. K. Chowdhury and Siva Umapathy, Faraday Discuss., 2010

DOI: $\underline{10.1039 / \mathrm{b} 908146 \mathrm{a}}$

Entropic trends in aqueous solutions of the common functional groups

Sheeba Jem Irudayam, Richard D. Plumb and Richard H. Henchman, Faraday Discuss., 2010

DOI: $10.1039 / \mathrm{b} 907383 \mathrm{c}$

$\underline{A b}$ initio transition state theory for polar reactions in solution

Jeremy N. Harvey, Faraday Discuss., 2010

DOI: 10.1039/b907340j

Electronic structures of [n]-cyclacenes $(n=6-12)$ and short, hydrogen-capped, carbon nanotubes

Daniel Sadowsky, Kristopher McNeill and Christopher J.

Cramer, Faraday Discuss., 2010

DOI: $\underline{10.1039 / b 906882 a}$

Discussion

General discussion

Faraday Discuss., 2010

DOI: $10.1039 / \mathrm{b} 921493 \mathrm{n}$

Concluding remarks

Concluding remarks

Josef Michl, Faraday Discuss., 2010

DOI: $\underline{10.1039 / \mathrm{b} 923060 \mathrm{~m}}$ 


\title{
Dynamic path bifurcation for the Beckmann reaction: observation and implication
}

\author{
Hiroshi Yamataka, * Makoto Sato, Hiroto Hasegawa \\ and Salai C. Ammal
}

\author{
Received 1st April 2009, Accepted 15th April 2009 \\ First published as an Advance Article on the web 23rd September 2009 \\ DOI: 10.1039/b906159b
}

\begin{abstract}
The reaction of oximes to amides, known as the Beckmann rearrangement, may undergo fragmentation to form carbocations + nitriles instead of amides when the cations have reasonable stability. The reactions of oxime derivatives of 1-substituted-phenyl-2-propanones and 3-substituted-phenyl-2-butanones in aqueous solvents gave both rearrangement and fragmentation products, the ratio of which was dependent on substituents. Transition state (TS) optimizations and intrinsic reaction coordinate (IRC) calculations for the reaction of 1-phenyl-2propanone oximes showed that there is a single TS for each substituted compound. The IRC path from the TS either led to a rearrangement product or a fragmentation product depending on the substituent; the IRC path changes from rearrangement to fragmentation when substituent $\mathrm{X}$ becomes more electron donating. Ab initio dynamics simulations were found to follow the IRC path for $\mathrm{X}=p-\mathrm{NH}_{2}$ and $p-\mathrm{MeO}$ giving fragmentation products, and almost so for $\mathrm{X}=$ $p-\mathrm{NO}_{2}$ giving the rearrangement products. However, in a borderline case where $\mathrm{X}$ is less donating than $p-\mathrm{MeO}$ or less withdrawing than $p-\mathrm{NO}_{2}$, the trajectories did not follow the minimum energy path on the potential energy surface, but gave both rearrangement and fragmentation products directly from the single TS. This is a novel example of path bifurcation for a closed shell anionic reaction. It was concluded that a reactivity-selectivity argument based on the traditional TS theory may not always be applicable even to a well-known textbook organic reaction.
\end{abstract}

\section{Introduction}

When an organic reaction yields two products, the kinetic selectivity is viewed as arising from the relative rates of the two concurrent pathways leading to the two products. Accordingly, high-selective synthetic reactions have often been designed to stabilize the transition state (TS) of the main reaction relative to that for a minor product. To study organic reaction mechanisms, it has become a common practice to use molecular orbital (MO) methods and to calculate TS structures and in some cases potential energy surfaces (PESs). Although MO calculations have achieved numerous contributions in the field of mechanistic organic chemistry, it should be noted that the calculated structures, energies and reaction pathways are at $0 \mathrm{~K}$, and therefore information obtained from MO calculations may not directly be related to experimental observations at a finite temperature.

It has been increasingly recognized by means of molecular dynamics (MD) simulation studies that dynamics effects play a crucial role in controlling the reaction

Department of Chemistry and the Research Center for Smart Molecules, Rikkyo University, Nishi-Ikebukuro, Toshima-ku, 171-8501 Tokyo, Japan. E-mail: yamataka@rikkyo.ac.jp 
mechanism for mechanistically borderline reactions. ${ }^{1}$ In a pioneering study reported in 1985, Carpenter demonstrated a possible role of dynamics effect in chemical reactions. He showed by using a model PES that when two symmetrical products were formed from a common intermediate through isoenergetic barriers, the two products might be obtained in unequal amounts depending on how the common intermediate was formed. ${ }^{2}$ This was a new interpretation of an old idea, a memory effect. Since then, dynamics effects have been claimed to play an important role in various reactions. It appears in different ways, such as nonstatistical barrier recrossing, ${ }^{3}$ nonstatistical product distribution, ${ }^{4}$ shallow minimum skip on the intrinsic reaction coordinate (IRC), ${ }^{5}$ non-IRC path, ${ }^{6-8}$ and path bifurcation. ${ }^{9,10}$ All these results suggested that the mechanism of these reactions could not be defined by the reaction paths on the PES and by the traditional TS theory.

The Beckmann rearrangement is a textbook reaction, in which oximes under acidic conditions or those with an appropriate leaving group (Y) under solvolytic conditions give amide via intramolecular rearrangement (path $a$ in eqn (1)). Oximes have been known to give fragmentation products when the $\mathrm{R}^{1}$ group, which is located anti to $\mathrm{Y}$, is stabilized as a cation by an adjacent group, such as $\mathrm{O},{ }^{11} \mathrm{~S},{ }^{12}$ $\mathrm{N},{ }^{13} \mathrm{Si}^{14}$ and $\mathrm{CH}=\mathrm{CHR} .{ }^{15}$ Grob et al. reported in 1964 that the reaction of ketoxime tosylate (1, Y $=$ OTs) in $80 \%$ aq. EtOH gave two types of products and that the percentage of the fragmentation product $(\mathrm{F} /(\mathrm{F}+\mathrm{R}))$ increased when the $\mathrm{R}^{1}$ group became better stabilized as a cation $\left(\mathrm{R}^{1}=\mathrm{CHPh}_{2}>t\right.$ - $\mathrm{Bu}>i$-Pr $) .{ }^{16} \mathrm{On}$ the other hand, the reactivity was found not to follow the same order $\left(\mathrm{R}^{1}=t-\mathrm{Bu}>i-\mathrm{Pr}>\right.$ $\mathrm{Ph}>\mathrm{Et}>\mathrm{CHPh}_{2}$ ). Thus, the product selectivity and the reactivity were controlled in different steps.

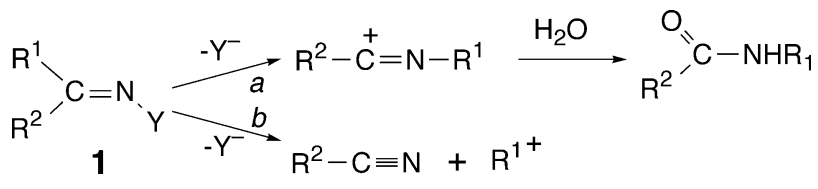

Preliminary molecular orbital (MO) calculations from our laboratory have shown that the reactions of ring-substituted 1-phenyl-2-propanone oxime derivatives $\left(1, \mathrm{R}^{1}=\mathrm{XC}_{6} \mathrm{H}_{4} \mathrm{CH}_{2}, \mathrm{R}^{2}=\mathrm{CH}_{3}, \mathrm{Y}=\mathrm{OH}_{2}{ }^{+}\right)$gave either a fragmentation or a rearrangement product depending on the substituent through a single TS on the PES. ${ }^{17}$ The IRC reached the fragmentation product region for $\mathrm{X}=p-\mathrm{MeO}$, whereas it gave the rearranged product for $\mathrm{X}=p-\mathrm{Me}, \mathrm{H}, p-\mathrm{CN}, p-\mathrm{NO}_{2}$. Thus, the reaction mechanism switched through the variation of the nature of a single TS rather than the variation of relative feasibility of concurrent reactions.

In this paper, the results of a combined experimental and computational study will be discussed, with stress on the dynamics effect on the reaction mechanism. In particular, possible occurrence and the origin of path bifurcation will be analyzed.

\section{Results and discussion}

\section{Experimental results}

The reactions of ring substituted 1-phenyl-2-propanone oxime 2-naphthalenesulfonates (2-X) and 3-phenyl-2-butanone oxime 2-naphthalenesulfonates (3-X) were examined in aq. $\mathrm{MeOH}$ and aq. $\mathrm{MeCN}$ at $25^{\circ} \mathrm{C}$ (eqn (2)). The reaction of $\mathbf{2}-\mathbf{H}$ in aq. $\mathrm{MeOH}$ gave the corresponding amide (4-X) as a major product, together with small amounts of benzyl alcohol (5-X) and benzyl ether. Thus, the major product was from the rearrangement process. In order to analyze closely the correlation between the product ratio and the overall reactivity, we chose aq. $\mathrm{MeCN}$ as the solvent system, where the product composition was simple with only amide 
(rearrangement) and alcohol (fragmentation) as each type of the product and the reaction rates were conveniently measured by a spectroscopic method. The rates and product distributions of the reactions of $\mathbf{2 - X}$ and $\mathbf{3 - X}$ were determined in aq. $\mathrm{MeCN}$ at $25{ }^{\circ} \mathrm{C}$. The first-order rate constants are summarized together with the product ratio in Table 1. Although the experimental study is still in a preliminary stage in terms of the number and the type of substituent, the data in Table 1 clearly shows that substrates 3-X, especially those with electron-donating substituents, yielded a significant amount of fragmentation product in addition to the rearrangement product. Despite the difference in the product composition, the relative reactivities for the two systems (2-X and $\mathbf{3 - X}$ ) gave reasonably good linear correlation (Fig. 1).
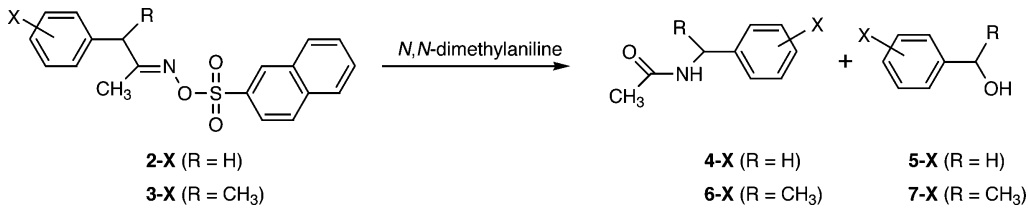

There are three possible explanations for the results. First, the two products are formed via competitive pathways as in eqn (1). This explanation is unlikely, since this requires the two TSs to have similar electron demand, despite the electron demand in the intermediates being very different. It is also not consistent with the preliminary computational result that there was only one TS on the PES for protonated 1-phenyl-2-propanone oxime $\left(1, \mathrm{R}^{1}=\mathrm{XC}_{6} \mathrm{H}_{4} \mathrm{CH}_{2}, \mathrm{R}^{2}=\mathrm{CH}_{3}, \mathrm{Y}=\mathrm{OH}_{2}{ }^{+}\right)$ leading to either the fragmentation or the rearrangement product..$^{17}$ In the second interpretation, these reactions go through a TS to give the rearranged intermediate $\left(\mathrm{CH}_{3} \mathrm{C}^{+}=\mathrm{NCHRAr}, \mathrm{R}=\mathrm{H}\right.$ or $\left.\mathrm{Me}\right)$, which may afford amide upon hydrolysis or $\mathrm{MeCN}+$ benzylic cation upon $\mathrm{N}-\mathrm{C}$ bond cleavage. Thus, the rate-determining and product-determining steps are different steps with a common intermediate for the two products. It is difficult to eliminate the possibility completely by experiment, but this explanation requires that the $\mathrm{N}-\mathrm{C}$ bond cleavage in the cationic intermediate is competitive with the attack of solvent water on the cation. The former step is endothermic at least in the gas phase $\left(8.7\right.$ (20.8) $\mathrm{kcal} \mathrm{mol}^{-1}$ in free energy for $2-\mathbf{H}$ at $\mathrm{HF} / 6-31 \mathrm{G}^{*}$ (MP2/6-31G*)), whereas the latter step is likely to be exothermic and very fast in aq. solvent. Finally, the third interpretation is that the reactions proceed through a single TS and the path bifurcates afterwards to give the two products. Recently, path bifurcation phenomena have been reported in several reactions, ${ }^{9,10}$ most of which involve open-shell species. It is important to

Table 1 First-order rate constants and the product ratios at $25{ }^{\circ} \mathrm{C}$ for the reactions of substituted 1-phenyl-2-propanone oxime 2-naphthalenesulfonates (2-X) in $80 \%$ (v/v) aq. $\mathrm{MeCN}$ and of substituted 3-phenyl-2-butanone oxime 2-naphthalenesulfonates (3-X) in $90 \%$ (v/v) aq. $\mathrm{MeCN}$

\begin{tabular}{llllll}
\hline & $\mathbf{2 - X}$ & & $\mathbf{3 - X}$ \\
\cline { 2 - 3 } \cline { 5 - 6 } $\mathrm{X}$ & $k / \times 10^{-5} \mathrm{~s}^{-1}$ & $\mathrm{R} /(\mathrm{F}+\mathrm{R})$ ratio $^{a}$ & & $k / \times 10^{-4} \mathrm{~s}^{-1}$ & $\mathrm{R} /(\mathrm{F}+\mathrm{R})$ ratio $^{a}$ \\
\hline$p-\mathrm{CH}_{3}$ & $241 \pm 4$ & 92.4 & 114 & 46.7 \\
$\mathrm{H}$ & $81.5 \pm 17$ & 100.0 & 40.7 & 78.7 \\
$p-\mathrm{Cl}$ & $28.2 \pm 16$ & $\mathrm{nd}^{b}$ & 15.4 & 79.6 \\
$m-\mathrm{Cl}$ & $10.1 \pm 0.1$ & $\mathrm{nd}^{b}$ & 5.52 & 94.2 \\
$p-\mathrm{CF}_{3}$ & $4.52 \pm 0.05$ & $\mathrm{nd}^{b}$ & 2.46 & 98.4 \\
${ }^{a}$ The percentage of the rearrangement product over the total product. ${ }^{b}$ Not determined. \\
\hline
\end{tabular}




\begin{tabular}{|c|c|c|c|c|c|}
\hline \multicolumn{6}{|c|}{$\begin{array}{l}\text { Table } 2 \text { Calculated activation energies at } \mathrm{HF} / 6-31 \mathrm{G}^{*} \text { and at } \mathrm{MP} 2 / 6-31 \mathrm{G}^{*} \text {, and selected TS } \\
\text { geometrical parameters at MP2/6-31G* for the reactions of } \mathbf{8 - X}\end{array}$} \\
\hline $\mathrm{X}$ & Activation energy $y^{a, b}$ & Activation energy ${ }^{a, c}$ & $R_{\mathrm{C}-\mathrm{C}}{ }^{d}$ & $\theta_{\mathrm{CCN}}^{e}$ & $R_{\mathrm{N}-\mathrm{O}}^{f}$ \\
\hline$p-\mathrm{NH}_{2}$ & $13.5(13.6)$ & $22.9(24.3)$ & 1.604 & 102.9 & 1.852 \\
\hline$p-\mathrm{MeO}$ & $15.3(15.5)$ & $25.0(26.5)$ & 1.614 & 101.5 & 1.880 \\
\hline$p-\mathrm{Me}$ & $15.8(15.7)$ & $26.0(27.3)$ & 1.623 & 100.0 & 1.911 \\
\hline$m, m^{\prime}-\mathrm{Me}_{2}$ & $15.4(15.2)$ & $25.4(26.5)$ & 1.622 & 99.8 & 1.914 \\
\hline$m-\mathrm{Me}$ & $16.0(16.3)$ & $26.3(27.5)$ & 1.626 & 99.3 & 1.923 \\
\hline $\mathrm{H}$ & $16.8(16.8)$ & $27.4(28.7)$ & 1.629 & 98.9 & 1.930 \\
\hline$p-\mathrm{Cl}$ & $20.3(20.1)$ & $30.4(31.6)$ & 1.636 & 98.6 & 1.937 \\
\hline$p$-CHO & $21.5(21.3)$ & $31.9(33.0)$ & 1.639 & 97.6 & 1.953 \\
\hline$p$-CN & $24.5(24.1)$ & $34.7(35.8)$ & 1.647 & 96.8 & 1.968 \\
\hline$p-\mathrm{NO}_{2}$ & $26.0(25.4)$ & $35.3(36.4)$ & 1.650 & 96.1 & 1.978 \\
\hline \multicolumn{6}{|c|}{$\begin{array}{l}{ }^{a} \Delta H^{\ddagger}\left(\Delta G^{\ddagger}\right) \text { in kcal mol }{ }^{-1} \text { with respect to separated reactants. }{ }^{b} \text { Energies at HF. }{ }^{c} \text { Energies at } \\
\text { MP2. }{ }^{d} \text { Distance between benzylic carbon and imino carbon in } \AA .{ }^{e} \text { In degrees. }{ }^{f} \text { In } \AA \text {. }\end{array}$} \\
\hline
\end{tabular}

smooth TS variation itself is suggestive of the same reaction mechanism for all substituted substrates.

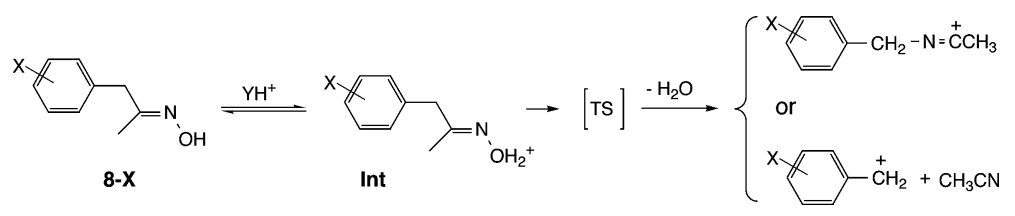

Relative activation enthalpies $\left(\Delta H^{*}\right)$ in Table 2 were converted to $\log \left(k_{\mathrm{X}} / k_{\mathrm{H}}\right)$ at $298 \mathrm{~K}$, and were plotted against the Hammett $\sigma$ constants in Fig. 3. Here, we used enthalpies, because the size of the entropy and hence the free energy depend

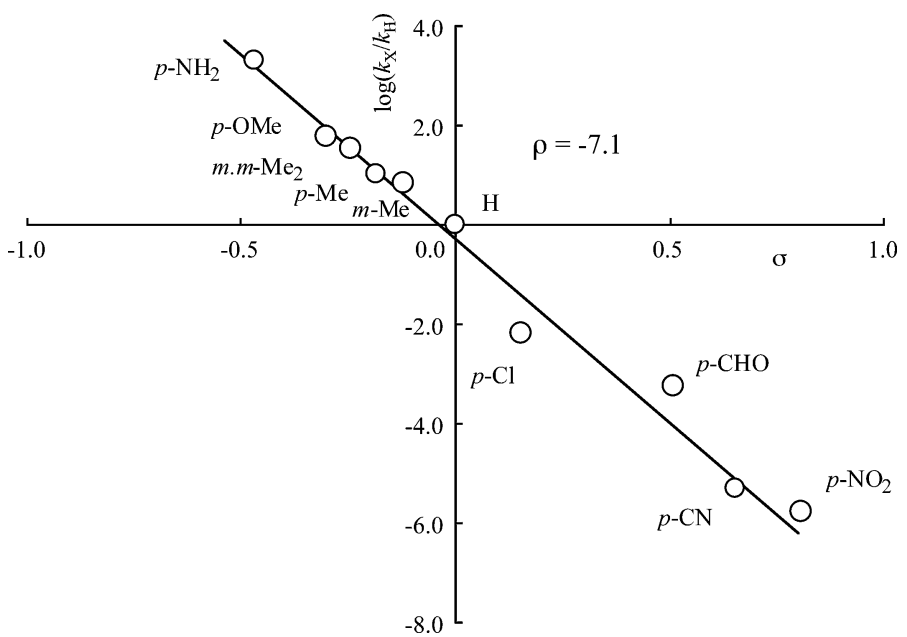

Fig. 3 Hammett plots for the reactions of 8-X. Relative reactivities at $298 \mathrm{~K}$ were calculated with the MP2/6-31G* enthalpies. 
much on low frequencies, which are less reliable than higher frequencies, especially for compounds with weak interactions such as TS. The use of free energy $\left(\Delta G^{\ddagger}\right)$ gave similar correlations with more scattered points. The $\sigma$ values were taken from gasphase experiments. ${ }^{19}$ The linear Hammett plots in Fig. 3 may be taken to suggest that the mechanism does not change as a function of substituent.

Although the TS structures and their energies appeared to suggest a common reaction mechanism for all substituted derivatives, IRC calculations revealed that the reaction mechanism varies depending on the electronic nature of the substituent as shown in Fig. 4. Here, the abscissa is the reaction coordinate and the ordinate is the atomic distance between the benzylic carbon and the nitrogen, and only the IRC traces toward the products are shown. The $\mathrm{C}-\mathrm{N}$ distance is shorter at the TS than at the reactant $(2.184 \AA$ vs. $2.286 \AA$, for $\mathrm{X}=\mathrm{H})$ and becomes as small as $1.4 \AA$ in the rearrangement product, whereas it becomes larger than $2.5 \AA$ in fragmentation. It can be seen that the IRC for substrates with an electron-withdrawing substituent reached the rearrangement product state with a short $\mathrm{C}-\mathrm{N}$ distance. On the other hand, the IRC for substrates with an electron-donating substituent led to the product with a long $\mathrm{C}-\mathrm{N}$ distance. The two computational methods ( $\mathrm{HF}$ and MP2) gave qualitatively the same results, in that the path switched from rearrangement to fragmentation when substituent became more electron donating. Overall, it is clear in Fig. 4 that the IRC pathway varies continuously with the substituent, from clear rearrangement $\left(p-\mathrm{NO}_{2}, p\right.$-CN and $p$-CHO) through borderline fragmentationrearrangement $\left(\mathrm{X}=p\right.$ - $\mathrm{Cl}, \mathrm{H}, m-\mathrm{Me}, m, m^{\prime}-\mathrm{Me}_{2}$, and $\left.p-\mathrm{Me}\right)$ to fragmentation ( $p-\mathrm{MeO}$ and $p-\mathrm{NH}_{2}$ at MP2) and that the product is either one of the two for each derivative, even for the borderline cases. As a result, despite the fact that the nature of the TS in terms of structure and energy varies smoothly with substituent, the reaction product and the reaction mechanism on the PES exhibit a sharp change as a function of the substituent.

The present findings indicate that mechanistic variation is not necessarily accompanied by a sharp variation in reactivity and TS structure, and hence experimentally observable quantities, such as relative reactivities (Hammett equation) and kinetic isotope effects, which are commonly considered to be useful means to detect a change in a reaction mechanism, may not always be useful.

\section{Trajectory calculations}

Direct-MD calculations starting at the TS of each substituted substrate (8-X) were carried out in order to see how the mechanism changes with substituent. Three methods, HONDO, PEACH and Gaussian (G03), were used, and a total of 810 trajectories were obtained at the HF/6-31G* level. In addition to trajectories that go back to the reactant (protonated oxime) region, three types of productive

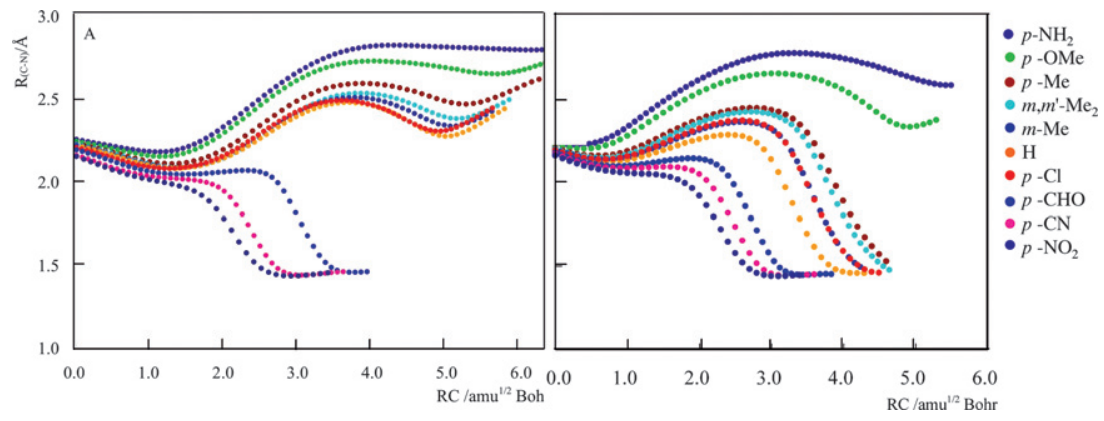

Fig. 4 IRC pathways for reaction (3) at (A) HF/6-31G* and (B) MP2/6-31G*. 
trajectories were observed: type $\mathrm{R}$ leading directly to the rearrangement region, type $\mathrm{F}$ leading directly to the fragmentation region, and type $\mathrm{R} \rightarrow \mathrm{F}$, which initially goes to the rearrangement region and then leads to the fragmentation product. Representative trajectories are illustrated in Fig. 5, in which the abscissa is the $\mathrm{N}-\mathrm{O}$ atomic

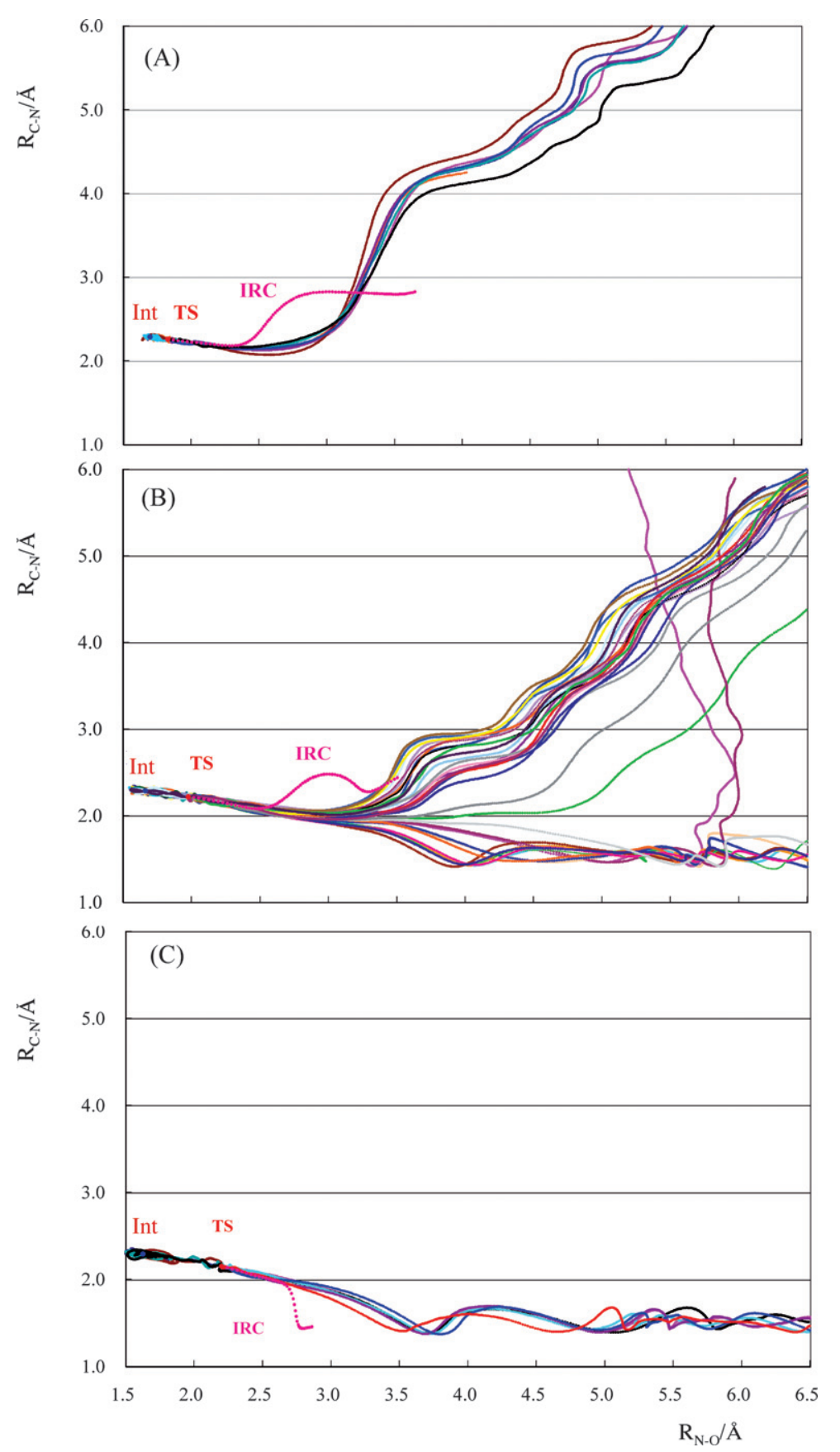

Fig. 5 Two-dimensional plots of MD trajectories obtained by PEACH at the initial kinetic energy of $50 \mathrm{~K}$ : (A) 8-p- $\mathrm{NH}_{2}$, (B) 8-H, and (C) 8-p- $\mathrm{NO}_{2}$. 
distance and the ordinate is the atomic distance between the benzylic carbon and the nitrogen. The results for $\mathbf{8 - p}-\mathbf{N H}_{\mathbf{2}}$ in Fig. 5A clearly indicate that all trajectories directly lead to the fragmentation region (type F). In Fig. $5 \mathrm{C}$ are shown the trajectories for 8-p- $\mathrm{NO}_{2}$, all of which are type R. Thus, trajectory calculations for these two substrates gave results that agreed with the IRC calculations. In contrast, simulations with one of the borderline substrates $(\mathbf{8}-\mathbf{H})$ gave both type $\mathrm{F}$ and $\mathrm{R}$ trajectories as illustrated in Fig. 5B.

Table 3 summarises the results of trajectory calculations for 10 substituted derivatives. There were trajectories that went back to the reactant region but afterward moved to the product regions, and these were counted as productive runs in Table 3. The type $\mathrm{R} \rightarrow \mathrm{F}$ trajectories were counted as type $\mathrm{R}$. It was found that the three methods gave qualitatively the same results. Substrates with an electron-donating substituent led to the fragmentation region exclusively, whereas those with an electron-withdrawing substituent gave predominantly the rearranged products. For the borderline substrates, trajectories from their respective TS gave both fragmentation

Table 3 Summary of the trajectory calculations

\begin{tabular}{|c|c|c|c|c|c|c|c|}
\hline $\mathrm{X}$ & $\operatorname{IRC}^{a}$ & Appl. & $n^{b}$ & $\mathrm{R}^{c}$ & $\mathrm{~F}^{d}$ & $\mathbf{R} \%{ }^{e}$ & $\mathrm{R} \rightarrow \mathrm{F}^{f}$ \\
\hline \multirow[t]{3}{*}{$p-\mathrm{NH}_{2}$} & \multirow[t]{3}{*}{$\mathrm{F}$} & G03 & 10 & 0 & 10 & 0 & 0 \\
\hline & & HONDO & $\mathrm{nd}^{g}$ & nd & nd & & \\
\hline & & PEACH & 10 & 0 & 8 & 0 & 0 \\
\hline \multirow[t]{3}{*}{$p-\mathrm{MeO}$} & \multirow[t]{3}{*}{$\mathrm{F}$} & G03 & 15 & 0 & 15 & 0 & \\
\hline & & HONDO & 10 & 0 & 9 & 0 & 0 \\
\hline & & PEACH & 10 & 0 & 9 & 0 & \\
\hline \multirow[t]{3}{*}{$p$-Me } & \multirow[t]{3}{*}{$\mathrm{F}$} & G03 & 20 & 3 & 17 & 15 & 0 \\
\hline & & HONDO & 20 & 0 & 19 & 0 & 0 \\
\hline & & PEACH & 20 & 0 & 13 & 0 & \\
\hline \multirow[t]{3}{*}{$m, m^{\prime}-\mathrm{Me}_{2}$} & \multirow[t]{3}{*}{$\mathrm{F}$} & G03 & 20 & 5 & 15 & 25 & 3 \\
\hline & & HONDO & nd & nd & nd & & \\
\hline & & PEACH & 20 & 1 & 12 & 8 & \\
\hline \multirow[t]{3}{*}{$m$-Me } & \multirow[t]{3}{*}{$\mathrm{F}$} & G03 & 30 & 12 & 18 & 40 & 8 \\
\hline & & HONDO & nd & nd & nd & & \\
\hline & & PEACH & 30 & 4 & 20 & 17 & \\
\hline \multirow[t]{3}{*}{$\mathrm{H}$} & \multirow[t]{3}{*}{$\mathrm{F}$} & G03 & 50 & 12 & 36 & 25 & 5 \\
\hline & & HONDO & 50 & 6 & 24 & 20 & 1 \\
\hline & & PEACH & 50 & 13 & 21 & 38 & 10 \\
\hline \multirow[t]{3}{*}{$p-\mathrm{Cl}$} & \multirow[t]{3}{*}{$\mathrm{F}$} & G03 & 50 & 9 & 39 & 19 & 1 \\
\hline & & HONDO & 50 & 9 & 23 & 28 & 0 \\
\hline & & PEACH & 50 & 10 & 23 & 30 & 3 \\
\hline \multirow[t]{3}{*}{$p$-CHO } & \multirow[t]{3}{*}{$\mathrm{R}$} & G03 & 50 & 34 & 16 & 68 & 4 \\
\hline & & HONDO & 50 & 29 & 3 & 91 & 0 \\
\hline & & PEACH & 50 & 32 & 1 & 97 & 0 \\
\hline \multirow[t]{3}{*}{$p$-CN } & \multirow[t]{3}{*}{$\mathrm{R}$} & G03 & 30 & 22 & 8 & 73 & 5 \\
\hline & & HONDO & 20 & 20 & 0 & 100 & 0 \\
\hline & & PEACH & 20 & 11 & 0 & 100 & \\
\hline \multirow[t]{3}{*}{$p-\mathrm{NO}_{2}$} & \multirow[t]{3}{*}{$\mathrm{R}$} & G03 & 15 & 14 & 1 & 93 & 2 \\
\hline & & HONDO & 10 & 8 & 0 & 100 & 0 \\
\hline & & PEACH & 10 & 6 & 0 & 100 & \\
\hline
\end{tabular}

${ }^{a}$ IRC leading to rearrangement (R) or fragmentation (F) product. ${ }^{b}$ Number of trajectories.

${ }^{c}$ Number of trajectories that lead to the rearrangement region. ${ }^{d}$ Number of trajectories that lead to the fragmentation region. ${ }^{e} \%$ Rearrangement $100(\mathrm{R} /(\mathrm{R}+\mathrm{F})) .{ }^{f}$ Number of trajectories that first go to the rearrangement region and then lead to the fragmentation product region.

${ }^{g}$ Not determined. 
and rearrangement products directly. The results with G03 showed more mixture than those with other two methods, probably due to the difference in the initial sampling procedure. The fact that the same trends were observed qualitatively indicates that the present results are not due to any artifact in the simulation methods.

Path bifurcation. The fact that the trajectories starting from a single TS led to two products indicates that the reaction path bifurcates dynamically on the way from the TS to the products, despite the IRC path on the PES being connected to either one of the two products for each borderline substrate. The path bifurcation violates the TSbased reaction theory and thus suggests that a TS of a given character may have only limited significance with respect to the actual mechanism.

The effect of kinetic temperature on the trajectory was examined by running the simulations at $10 \mathrm{~K}$ for three borderline substrates with PEACH. In contrast to the higher temperature trajectories, in which the three substrates gave a mixture of type $\mathrm{F}$ and $\mathrm{R}$ trajectories as mentioned above, $\mathbf{8}-\mathbf{H}$ ( 20 productive runs) and $\mathbf{8 - p}-\mathbf{C l}$ (20 productive runs) gave only type $\mathrm{F}$ trajectories, and 8-p-CHO (20 productive runs) gave only type $\mathrm{R}$ trajectories. Thus, the low temperature trajectories followed the IRC paths. It is clear that the dynamic path bifurcation is kinetic energy dependent.

Comparison of MD trajectories in Fig. 5 with IRC revealed that trajectories initially following the IRC paths start to deviate at $R_{\mathrm{N}-\mathrm{O}}=2.5 \AA$ in type $\mathrm{F}$ (Fig. 5A) and $2.7 \AA$ in type $\mathrm{R}$ (Fig. 5C) from IRC in such a way that the $\mathrm{N}-\mathrm{O}$ bond cleavage continues to occur ahead of the benzyl group departure (type $\mathrm{F}$ ) or the $\mathrm{C}-\mathrm{N}$ bond formation (type $\mathrm{R}$ ). Thus, both the fragmentation and rearrangement processes are concerted on the PES, whereas they are rather asynchronous two-stage processes in dynamics. The phenomenon is reminiscent of formally concerted and dynamically two-stage reactions reported in the literature. ${ }^{7,8,20}$

Origin of bifurcation. Path bifurcation has been observed in previous direct-MD simulations for a few reactions in the literature. ${ }^{9,10}$ Most of them are related to a symmetrical PES, in which a minimum energy path (MEP) from the TS that separates the reactant and product regions leads through a valley-ridge inflection (VRI) point to another TS separating two symmetrical products. ${ }^{21}$ Trajectories starting from the first TS proceed toward the second TS and bifurcate before reaching the second TS to give two products in statistically equal amounts. When a small perturbation, such as an isotope or a remote substituent, is introduced, the two products would be formed in different amounts. ${ }^{9}$ The product ratio is controlled by the way trajectories adopt the course on the way from the first TS to the second TS. Path bifurcation may occur on a different type of PES, in which MEP from a TS leads to one product that is separated by the second TS from another product located nearby on the PES. ${ }^{10}$ Bifurcation on such an asymmetrical PES may occur when trajectories move off the MEP dynamically and get over a barrier toward the second product region.

The present Beckmann rearrangement/fragmentation falls in the second category. In this case, trajectories from the TSs for 8-X $\left(\mathrm{X}=p-\mathrm{NH}_{2}, p-\mathrm{MeO}\right)$ led to the fragmentation product region, whereas those for 8-X $\left(\mathrm{X}=p-\mathrm{NO}_{2}\right.$, $p-\mathrm{CN}$ ) went mostly to the rearrangement product region. In these cases, the trajectories basically followed the IRCs. For other borderline substrates, however, trajectories starting from the respective TS bifurcated and led to two product regions, despite that IRCs lead either of the two regions. It is important to point out that more F-type trajectories were detected for $\mathbf{8 - X}$ with a more electrondonating substituent.

These observations are explained by the existence of the barrier separating the two product regions and the shift of the barrier with substituent. Two-dimensional PESs near the product regions of 8-H and 8-p-CN are illustrated in Fig. 6, in which the abscissa is the $\mathrm{CH}_{2}-\mathrm{N}-\mathrm{CH}_{2} \mathrm{Ar}$ angle and the ordinate is the $\mathrm{N}-\mathrm{CH}_{2} \mathrm{Ar}$ distance. 

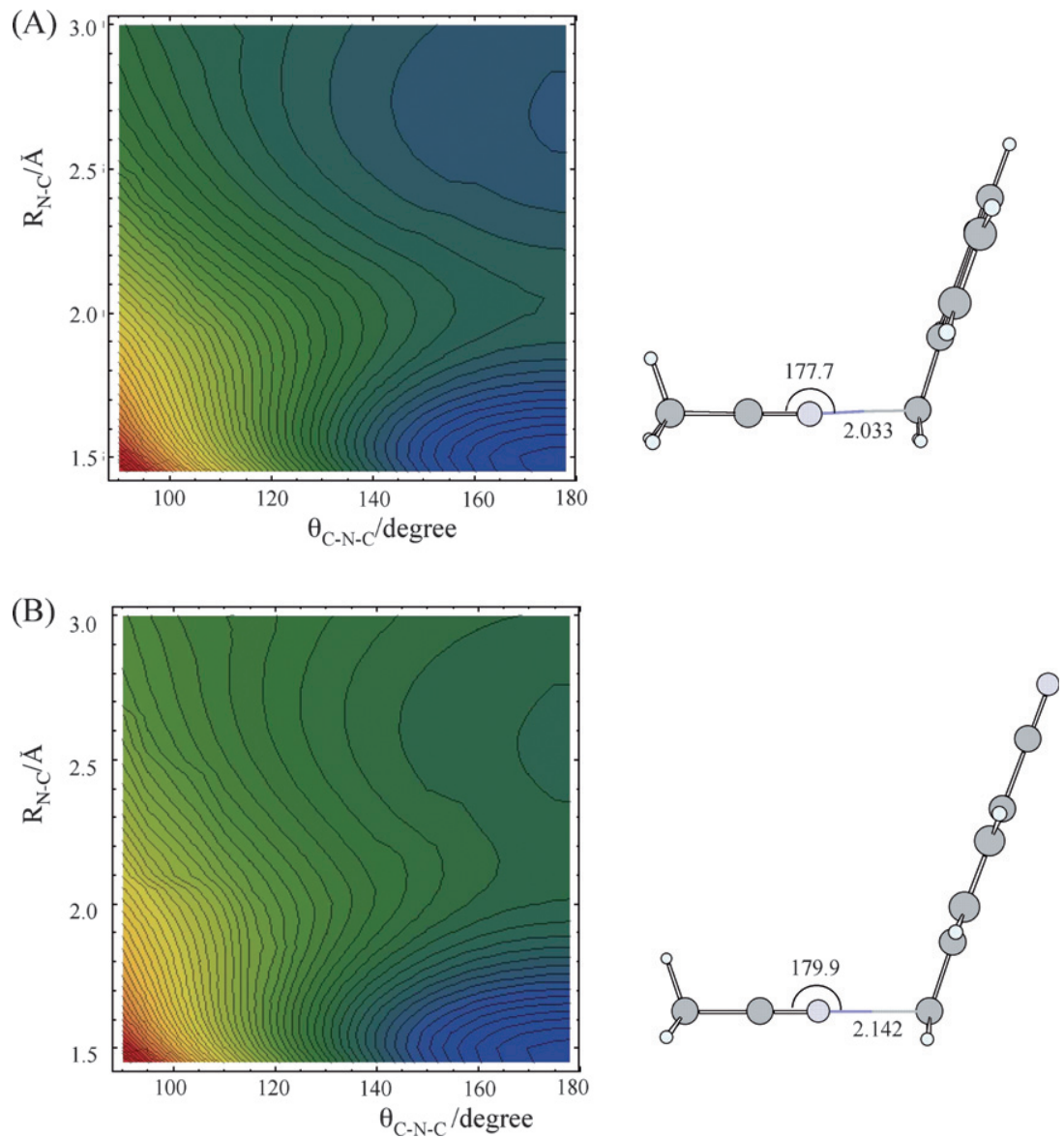

Fig. 6 Two-dimensional PESs and the TS structures between the two product regions for (A) 8-H and (B) 8-p-CN. The abscissa is the angle $\mathrm{C}-\mathrm{N}-\mathrm{CH}_{2} \mathrm{Ar}$ in degrees and the ordinate is the atomic distance $\mathrm{CN}-\mathrm{CH}_{2} \mathrm{Ar}$ in $\AA$.

The leaving group is not included in the PES calculations, since the inclusion of $\mathrm{H}_{2} \mathrm{O}$ requires impractical three-dimensional treatments. Thus, the PESs in Fig. 6 are not the exact surfaces of the reactions, but they are nevertheless useful to examine the shape of the surfaces qualitatively, especially near the product regions where the leaving group is nearly cleaved. The PES and the structures of the TSs separating the two product regions in Fig. 6 illustrate that the barrier exists between the two product regions and that its location shifts with the substituent. Reaction trajectories coming down from the left toward the right of the map would reach either the fragmentation or rearrangement product region depending on the location of the barrier.

The MD trajectories follow the same courses as IRCs when the initial kinetic energy is small. By contrast, when enough kinetic energy is provided, simulations for the borderline substrates give both type $\mathrm{R}$ and $\mathrm{F}$ trajectories, due to wider variations of the trajectories. In such cases, more $F$ type trajectories would be observed for 8-X with a more electron-donating substituent, since the barrier shifts toward a less stable side of the products. Thus, since an electron-donating substituent makes the fragmentation product more stable, the barrier moves toward the rearrangement side, and then more trajectories go to the fragmentation side. The shift of the barrier 
seen in Fig. 6 is consistent with the Leffler-Hammond principle ${ }^{18}$ and agrees with the prediction by the Thornton rule. ${ }^{22}$

\section{Concluding remarks}

The MO calculations indicated that the reaction of $\mathbf{8 - X}$ goes through a single TS either for the rearrangement or fragmentation routes, and the rearrangement/fragmentation product switching occurs as a function of the substituent. The introduction of an electron-donating substituent into the phenyl ring changes the mechanism from the rearrangement for $\mathrm{X}=p-\mathrm{NO}_{2}, p-\mathrm{CN}, p-\mathrm{CHO}, \mathrm{H}, m-\mathrm{Me}, m, m^{\prime}-\mathrm{Me}_{2}$, and $p-\mathrm{Me}_{2}$ to fragmentation for $\mathrm{X}=p-\mathrm{MeO}$ and $p-\mathrm{NH}_{2}$ (at MP2). On the other hand, the overall reactivity increases with a more electron-donating substituent on the phenyl ring in such a manner that the relative reactivity follows nicely the Hammett equation, and the structure of the TS varies with $\mathrm{X}$ in a manner consistent with the Hammond postulate in spite of the mechanistic changes with substituent. It is implied that Hammett plots and analyses of TS structures may give incorrect information of the reaction mechanism.

Trajectory calculations revealed that two products are formed through a single TS for borderline substrates. It is concluded that a conventional reactivity-selectivity argument and mechanistic assignment based on the TS theory may not always be applicable even to a well-known textbook organic reaction.

It should also be noted that the dynamically determined product ratio is governed by the electronic nature of substituents in a manner consistent with traditional electronic theory. Thus, the computationally detected substituent effects on the product distribution are readily reconciled with traditional reaction theory, which means that such a path bifurcation phenomenon would not easily be detected by experiment, unless critical examinations of experimental results were made. Measurements of substituent effects and KIEs, which are common means to detect variation of TS structures and reaction mechanisms, should be planned with care, since these experimental methods applied to rate processes do not afford information of possible path bifurcation occurring after the TS.

Nevertheless, careful kinetic and product analyses may allow us to detect path bifurcation experimentally. When two products are formed via parallel reactions, the overall rate can be divided into individual reactions on the basis of the product ratio, and substituent effects for each reaction thus obtained should give a linear Hammett plot. If, on the other hand, two products are formed through path bifurcation after the rate-determining TS, the TS has little relevance to the product-determining mechanism, and therefore the above-mentioned method of dividing the overall rate into two individual rates is likely to fail. Thus, careful examination of the correlation between rates and product ratios for a series of substrates may allow detection of path bifurcation.

Although extensive kinetic and product analysis experiments are required to prove the path bifurcation, the present experimental results, though preliminary, appear to cast doubt in interpreting the results in terms of two concurrent reaction pathways as commonly assumed, and provide support for dynamics effect and the bifurcation for the Beckmann reaction.

\section{Experimental methods}

All substituted oximes were synthesized from corresponding benzaldehydes by nitroaldol with $\mathrm{EtNO}_{2},{ }^{23} \mathrm{Fe}$ reduction, ${ }^{24}$ and oximation with $\mathrm{NH}_{2} \mathrm{OH}$. The sulfonate esters, $\mathbf{2}-\mathbf{X}$ and $\mathbf{3}-\mathbf{X}\left(\mathrm{X}=p-\mathrm{CH}_{3}, \mathrm{H}, p-\mathrm{Cl}, m-\mathrm{Cl}\right.$, and $\left.p-\mathrm{CF}_{3}\right)$ were prepared by Tipson's method from the corresponding oximes and 2-naphthalenesulfonyl chloride in pyridine. ${ }^{25}$ The authentic samples of the reaction products $(\mathbf{4 - X}, \mathbf{5 - X}, \mathbf{6 - X}, \mathbf{7 - X})$ were either isolated from the reaction mixture or synthesized separately. 
The reaction rates were measured by running the reactions in $80 \%$ aq. $\mathrm{MeCN}$ for 2-X and $90 \%$ aq. $\mathrm{MeCN}$ for $\mathbf{3 - X}$ at $25.0 \pm 0.1{ }^{\circ} \mathrm{C}$ in the presence of 1.1 equiv. of $\mathrm{N}, \mathrm{N}$-dimethylaniline. All reactions proceeded quantitatively, and the rates were determined photometrically by following the decrease of the absorbances of the sulfonates at their absorption maxima at $325-326 \mathrm{~nm}$. Material balance and product distribution were measured by analyzing the reaction mixture after 10 half-lives by means of GC and HPLC. The sensitivities of the products in the GC and HPLC measurements were calibrated by using authentic samples, which gave the material balances of $101 \pm 4 \%$.

\section{Computational methods}

Reactants (8-X), Int, TSs, and products $\left(\mathrm{XC}_{6} \mathrm{H}_{4} \mathrm{CH}_{2}{ }^{+}, \mathrm{CH}_{3} \mathrm{CN}\right.$, and $\mathrm{CH}_{3} \mathrm{C}^{+}=\mathrm{NCH}_{2} \mathrm{C}_{6} \mathrm{H}_{4} \mathrm{X}$ ) were fully optimized both at $\mathrm{HF} / 6-31 \mathrm{G}^{*}$ and $\mathrm{MP} 2 / 6-$ $31 \mathrm{G}^{*}$ with Gaussian 03. ${ }^{26}$ Full frequency calculations were carried out for all optimized structures to confirm whether the structures are on a minimum or a saddle point on the PES. IRC calculations were performed for all TSs at both computational levels.

Trajectory calculations were carried out by using three different methods, HONDO $,{ }^{27} \mathrm{PEACH},{ }^{28}$ and $\mathrm{G} 03 .{ }^{26}$ The kinetic temperature was in most cases $50 \mathrm{~K}$, and some calculations with $10 \mathrm{~K}$ kinetic temperature were carried out for comparison. Simulations with HONDO were initiated at each TS for a series of substituted derivatives with initial atomic velocities assigned from a random Maxwell-Boltzmann distribution with the total kinetic energy consistent with the simulation temperatures and run with a step size of $0.5 \mathrm{fs}^{7}{ }^{7}$ The method did not adopt the quasiclassical simulation methodology that assigns zero-point vibrational energies to the harmonic modes of vibrations as initial conditions, in order to minimize a side effect from unrealistic zero-point energy flow from transverse vibrational modes into the reaction coordinate mode. A velocity rescaling algorithm similar in form to the constant temperature algorithm of Berendsen et al. ${ }^{29}$ was used with a relaxation time $t=2000$ fs to mimic a slow energy transfer between the solute and an imaginary solvent bath. Calculations with PEACH were carried out in the same manner as HONDO, except that total energy was preserved during the simulations. G03 trajectory calculations were performed for the TS of each substituted substrate with BOMD keyword, which adopts the Hessian-based predictorcorrector method and quasiclassical sampling.

\section{Acknowledgements}

The study was in part supported by the SFR aid by Rikkyo University. SCA thanks CREST project operated by the Japan Science and Technology Agency (JST).

\section{References}

1 B. K. Carpenter, Acc. Chem. Res., 1992, 25, 520; H. Yamataka and M. Aida, Bull. Chem. Soc. Jpn., 2002, 75, 2555; B. K. Carpenter, J. Phys. Org. Chem., 2003, 16, 858; D. H. Ess, S. E. Wheeler, R. G. Iafe, L. Xu, N. Çelebi-Ölçüm and K. N. Houk, Angew. Chem., Int. Ed., 2008, 47, 7592; H. Yamataka, Adv. Phys. Org. Chem., in press.

2 B. K. Carpenter, J. Am. Chem. Soc., 1985, 107, 5730.

3 L. Sun, W. L. Hase and K. Song, J. Am. Chem. Soc., 2001, 123, 5753; D. J. Mann and W. K. Hase, J. Am. Chem. Soc., 2002, 124, 3208; L. Sun, E. Chang, K. Song and W. L. Hase, Can. J. Chem., 2004, 82, 891; S. Cheon, K. Song and W. L. Hase, THEOCHEM, 2006, 771, 27.

4 B. A. Lyons, J. Pfeifer, T. H. Peterson and B. K. Carpenter, J. Am. Chem. Soc., 1993, 115, 2427; B. K. Carpenter, J. Am. Chem. Soc., 1995, 117, 6336; C. Doubleday, Jr., K. Bolton, G. H. Peslherbe and W. L. Hase, J. Am. Chem. Soc., 1996, 118, 9922; B. K. Carpenter, J. Am. Chem. Soc., 1996, 118, 10329; D. A. Hrovat, S. Fang, W. T. Borden and B. K. Carpenter, J. Am. Chem. Soc., 1997, 119, 5253; M. B. Reys and B. K. Carpenters, 
J. Am. Chem. Soc., 1998, 120, 1641; K. Bolton, W. L. Hase and C. Doubleday, Jr., J. Phys. Chem. B, 1999, 103, 3691; C. Doubleday, Jr., M. Nendel, K. N. Houk, D. Thweatt and M. Page, J. Am. Chem. Soc., 1999, 121, 4720; C. Doubleday, J. Phys. Chem. A, 2001, 105, 6333; C. Doubleday, G. Li and W. L. Hase, Phys. Chem. Chem. Phys., 2002, 4, 304; C. Doubleday, C. P. Suhrada and K. N. Houk, J. Am. Chem. Soc., 2006, 128, 90; A. E. Litovitz, I. Keresztes and B. K. Carpenter, J. Am. Chem. Soc., 2008, 130, 12085.

5 S. L. Debbert, B. K. Carpenter, D. A. Hrovat and W. T. Borden, J. Am. Chem. Soc., 2002, 124, 7896; J. A. Nummela and B. K. Carpenter, J. Am. Chem. Soc., 2002, 124, 8512; L. Sun, K. Song and W. L. Hase, Science, 2002, 296, 875; S. Anand and H. B. Schlegel, Phys. Chem. Chem. Phys., 2004, 6, 5166; M. Hamaguchi, M. Nakaishi, T. Nagai, T. Nakamura and M. Abe, J. Am. Chem. Soc., 2007, 129, 12981.

6 C. D. Berweger, W. F. Gunsteren and F. Müller-Plathe, Angew. Chem., Int. Ed., 1999, 38, 2609; D. Townsend, S. A. Lahankar, S. K. Lee, S. D. Chambreau, A. G. Suits, X. Zhang, J. Rheinecker, L. B. Harding and J. M. Bowman, Science, 2004, 306, 1158; A. Pomerantz, J. P. Camden, A. S. Chioiu, F. Ausfelder, N. Chawia, W. L. Hase and R. N. Zare, J. Am. Chem. Soc., 2005, 127, 16368.

7 S. C. Ammal, H. Yamataka, M. Aida and M. Dupuis, Science, 2003, 299, 1555.

8 T. Bekele, C. F. Christian, M. A. Lipton and D. A. Singleton, J. Am. Chem. Soc., 2005, 127, 9216.

9 T. Taketsugu, T. Yanai, K. Hirao and M. S. Gordon, THEOCHEM, 1998, 451, 163; D. A. Singleton, C. Hang, M. J. Syzmanski and E. Greenwald, J. Am. Chem. Soc., 2003, 125, 1176; S. C. Ammal and H. Yamataka, Eur. J. Org. Chem., 2006, 4327; A. G. Leach, K. N. Houk and C. S. Foote, J. Org. Chem., 2008, 73, 8511.

10 T. L. Windus, M. S. Gordon, L. W. Burggraf and L. P. Davis, J. Am. Chem. Soc., 1991, 113, 4356; H. Yamataka, M. Aida and M. Dupuis, Chem. Phys. Lett., 1999, 300, 583; V. Bakken, D. Danovich, S. Shaik and H. B. Schlegel, J. Am. Chem. Soc., 2001, 123, 130; T. Taketsugu and Y. Kumeda, J. Chem. Phys., 2001, 114, 6973; H. Yamataka, M. Aida and M. Dupuis, Chem. Phys. Lett., 2002, 353, 310; H. Yamataka, M. Aida and M. Dupuis, J. Phys. Org. Chem., 2003, 16, 475; J. Li, X. Li, S. Shaik and H. B. Schlegel, J. Phys. Chem. A, 2004, 108, 8526; C. P. Suhrada, S. Selçuki, N. Nendel, C. Cannizzaro, K. N. Houk, P.J. Rissing, D. Baumann and D. Hasselmann, Angew. Chem., Int. Ed., 2005, 44, 3548; J. Li, S. Shaik and H. B. Schlegel, J. Phys. Chem. A, 2006, 110, 2801; B. R. Ussing, C. Hang and D. A. Singleton, J. Am. Chem. Soc., 2006, 128, 7594; N. Çelebi-Ölçüm, D. H. Ess, V. Aviyente and K. N. Houk, J. Org. Chem., 2008, 73, 7472.

11 R. L. Autrey and P. W. Scullard, J. Am. Chem. Soc., 1968, 90, 4924; C. A. Grob and J. Ide, Helv. Chim. Acta, 1974, 57, 2562; C. A. Grob and J. Ide, Helv. Chim. Acta, 1974, 57, 2571.

12 D. Miljkovic, J. Petrovic, M. Stajic and M. Miljkovic, J. Org. Chem., 1973, 38, 3585.

13 H. P. Fischer, C. A. Grob and E. Renk, Helv. Chim. Acta, 1962, 45, 2539.

14 H. Nishiyama, K. Sakuta, N. Osaka and K. Itoh, Tetrahedron Lett., 1983, 24, 4021; P. F. Hudrik, M. A. Wauch and A. M. Hudlik, J. Organomet. Chem., 1984, 271, 69.

15 A. Hassner and E. G. Nash, Tetrahedron Lett., 1965, 6, 525; A. C. Huitric and S. D. Nelson, Jr., J. Org. Chem., 1969, 34, 1230; C. A. Grob and P. Wenk, Tetrahedron Lett., 1976, 17, 4191.

16 C. A. Grob, H. P. Fischer, W. Raudenbusch and J. Zer'genyi, Helv. Chim. Acta, 1964, 47, 1003.

17 S. C. Ammal and H. Yamataka, in Recent Developments in Carbocation and Onium Ion Chemistry, ed. K. K. Laali, American Chemical Society, Washington, DC, 2007, p. 364.

18 J. E. Leffler, Science, 1953, 117, 340; G. S. Hammond, J. Am. Chem. Soc., 1955, 77, 334.

19 C. Huh, C. H. Kang, H. W. Lee, H. Nakamura, M. Mishima, Y. Tsuno and H. Yamataka, Bull. Chem. Soc. Jpn., 1999, 72, 1083; M. Mishima, Mustanir, M. Fujio and Y. Tsuno, Bull. Chem. Soc. Jpn., 1996, 69, 2009.

20 M. Sato, H. Yamataka, Y. Komeiji, Y. Mochizuki, T. Ishikawa and T. Nakano, J. Am. Chem. Soc., 2008, 130, 2396.

21 W. Quapp, M. Hirsch and D. Heidrich, Theor. Chem. Acc., 2004, 112, 40, and references cited therein.

22 E. R. Thornton, J. Am. Chem. Soc., 1967, 89, 2915.

23 S. Miyano, H. Hokari and H. Hashimoto, Bull. Chem. Soc. Jpn., 1982, 55, 534.

24 H. B. Hass, A. G. Susie and R. L. Heider, J. Org. Chem., 1950, 15, 8.

25 R. S. Tipson, J. Org. Chem., 1944, 9, 235.

26 M. J. Frisch, G. W. Trucks, H. B. Schlegel, G. E. Scuseria, M. A. Robb, J. R. Cheeseman, J. A. Montgomery, Jr., T. Vreven, K. N. Kudin, J. C. Burant, J. M. Millam, S. S. Iyengar, J. Tomasi, V. Barone, B. Mennucci, M. Cossi, G. Scalmani, N. Rega, G. A. Petersson, H. Nakatsuji, M. Hada, M. Ehara, K. Toyota, R. Fukuda, J. Hasegawa, M. Ishida, T. Nakajima, Y. Honda, O. Kitao, H. Nakai, M. Klene, X. Li, J. E. Knox, H. P. Hratchian, J. B. Cross, V. Bakken, C. Adamo, J. Jaramillo, R. Gomperts, 
R. E. Stratmann, O. Yazyev, A. J. Austin, R. Cammi, C. Pomelli, J. Ochterski, P. Y. Ayala, K. Morokuma, G. A. Voth, P. Salvador, J. J. Dannenberg, V. G. Zakrzewski, S. Dapprich, A. D. Daniels, M. C. Strain, O. Farkas, D. K. Malick, A. D. Rabuck, K. Raghavachari, J. B. Foresman, J. V. Ortiz, Q. Cui, A. G. Baboul, S. Clifford, J. Cioslowski, B. B. Stefanov, G. Liu, A. Liashenko, P. Piskorz, I. Komaromi, R. L. Martin, D. J. Fox, T. Keith, M. A. Al-Laham, C. Y. Peng, A. Nanayakkara, M. Challacombe, P. M. W. Gill, B. G. Johnson, W. Chen, M. W. Wong, C. Gonzalez and J. A. Pople, GAUSSIAN 03 (Revision C.02), Gaussian, Inc., Wallingford, CT, 2004.

27 M. Dupuis, A. Marquez and E. R. Davidson, HONDO 2001, available from the Quantum Chemistry Program Exchange, Indiana University.

28 Y. Komeiji, M. Uebayasi, R. Takata, A. Shimizu, K. Itsukashi and M. Taiji, J. Comput. Chem., 1997, 18, 1546; Y. Komeiji, T. Ishikawa, Y. Mochizuki, H. Yamataka and T. Nakano, J. Comput. Chem., 2009, 30, 40.

29 H. J. C. Berendsen, J. P. M. Postma, W. F. Van Gunsteren, A. DiNola and J. R. Haak, J. Chem. Phys., 1984, 81, 3684. 